\title{
ESPAÇO E AS REPRESENTAÇÕES SOCIAIS DOS MORADORES DE PRÉ-ASSENTAMENTO EMILIANO ZAPATA
}

\author{
space and social representations of the residents from \\ pre-settlement Emiliano Zapata
}

\author{
Fernando Bertani Gomes * \\ Joseli Maria Silva **
}

\begin{abstract}
Resumo
A pesquisa tem como objetivo compreender o espaço do Pré-assentamento e sua relação com as representações sociais construídas pelos seus moradores. O espaço geográfico é um elemento componente das representações, ao mesmo tempo em que é alvo delas. Nesse sentido, foram realizadas onze entrevistas com pessoas que vivenciam o assentamento em foco por meio de entrevistas semi-estruturadas. A análise das entrevistas foi realizada por meio da metodologia de análise de conteúdo e a escola moscoviciana, bem como a nova Geografia Cultural foram os suportes epistemológicos da investigação. O pré-assentamento apresenta-se como um espaço de pressão a mudanças, dialogando aspectos multi-escalares, entre as propostas organizativas do MST e as múltiplas práticas espaciais das famílias que formam o assentamento.

Palavras-Chave: Espaço; Assentamento; Representações Sociais; Geografia Cultural.

Abstract

This research aims to understand the space of the settlement and its relation with the social representations compounded by its residents. The geographic space is a component element of representations, at same time that is its target. Thus, by structured interviews were made eleven interviews with people that live the settlement. The analysis of interviews was made by content analysis methodology and Moscovician School, as well as the new Cultural Geography were the supports epistemological of research. The settlement if show as a space of pressure and change and there is a dialog of multi-scalar aspects between the proposed organizational of MST and multiple spatial practices of the families who make up the settlement.
\end{abstract}

Key words: Space, Settlement, Social Representations, Cultural Geography.

\section{Resumen}

La investigación tiene como objetivo comprender el espacio del asentamiento y su relación con las representaciones sociales construidas por sus habitantes. El espacio geográfico es un elemento componente de las representaciones, al mismo tiempo que los recibe. Así se realizaron once entrevistas con las personas que experimentan el asentamiento en el foco a través de entrevistas semis-estructuradas. El análisis de los datos se realizó utilizando la metodología de análisis de contenido y la escuela de Moscovici, así como la nueva Geografía Cultural fueron los fundamentos epistemológicos de la investigación. El asentamiento aparece como un espacio de presión para cambios y hay un cuadro de diálogo de aspectos multi-escalar entre la organización propuesta del MST y múltiples prácticas espaciales de las familias que componen el asentamiento.

Palabras-claves: Espacio, Asentamiento, Representaciones Sociales, Geografía Cultural.

(*) Prof. Msc. do Departamento de Geociências da Universidade Estadual de Ponta Grossa - Avenida Carlos Cavalcanti, 4.746, Uvaranas, CEP: 84030-900, Ponta Grossa (PR) - Brasil, Tel: (+55 42) 3220-3044 - ferbg28@gmail.com

(**) Prof ${ }^{a}$ Dr $^{\mathrm{a}}$ do Programa de Pós-Graduação em Geografia da Universidade Estadual de Ponta Grossa - Avenida Carlos Cavalcanti, 4.748, CIPP, sala LP 111, Uvaranas, CEP: 84030-900, Ponta Grossa (PR) - Brasil, Tel:(+55 42) 3220-3155 - joseli. genero@gmail.com 


\section{INTRODUÇÃO}

A pesquisa se voltou à compreensão da relação entre as Representações Sociais do Pré-assentamento Emiliano Zapata construídas pelos seus moradores e o espaço. Tal caminho de pesquisa se deu pelo fato de que, apesar da área enfocada ter sido conquistada pelo Movimento dos Trabalhadores Sem Terra (MST), há uma diversidade de pessoas que ali vivem, constituindo uma diversidade de ideias obscurecidas pela homogeneidade do movimento político. Portanto, este trabalho emerge da complexidade social da prática cotidiana dos moradores a evidenciar estruturas identitárias e formas de vida a construir tanto coesões como conflitos entre os moradores em foco.

Para operacionalizar a pesquisa balizadora do presente documento, foram realizadas entrevistas com 11 pessoas, por meio de um roteiro de entrevista semi-estruturado que tinha os seguintes eixos norteadores: 1) Processo de ocupação da área; 2) Período de acampamento; 3 ) Processo de distribuição dos lotes; 4) Atividades cotidianas; 5) Relações cotidianas e o MST. O número de pessoas entrevistadas foi definido por meio do método da "saturação", proposta por Sá (1998). Para ele, a amostra de pessoas a serem investigadas não deve ser definida à priori, mas na medida em que a pesquisa avança e as respostas tornam-se repetitivas, significa que se atingiu um número razoável de entrevistas para a análise pretendida. As entrevistas foram transcritas na íntegra e analisadas por meio de técnicas de análise de conteúdo, tal como proposto por Bardin (1977). A sistematização das entrevistas considerou a frequência de enunciados trazidos pelas pessoas entrevistadas, gerando os eixos de categorias discursivas que constituíram os resultados que serão apresentados no texto.

O texto está estruturado em duas partes. Na primeira, são apresentadas as aproximações possíveis entre a teoria das representações sociais da escola moscoviciana e o espaço, bem como a contextualização do pré-assentamento Emiliano Zapata, tomada como referencial empírico de análise. Na segunda parte são evidenciadas as representações sociais que se constroem por meio da prática do trabalho e da organização política do pré-assentamento, assim como os feixes de tensões e alianças políticas que constituem aquela espacialidade.

\section{ESPAÇO E REPRESENTAÇÕES SOCIAIS: uma aproximação para análise do Pré- assentamento Emiliano Zapata.}

O referencial empírico de análise é o Pré-assentamento Emiliano Zapata, organizado pelo Movimento dos Trabalhadores Rurais Sem Terra (MST). A área ainda se configura como um 'pré-assentamento', sem regularização da terra mediante o Instituto Nacional de Colonização e Reforma Agrária (INCRA). Entretanto, as famílias ali residentes já obtiveram avanços através da distribuição provisória de lotes e pela instituição de uma associação chamada Associação dos Trabalhadores Rurais da Reforma Agrária (ATERRA), o que tem possibilitado avanços na produção e comercialização de produtos, contribuindo para a permanência das famílias no local.

O Pré-assentamento localiza-se na porção sudeste cerca de $10 \mathrm{~km}$ da área urbana de Ponta Grossa. A entrada principal do Pré-assentamento pode ser acessada pela rodovia PR 513, conhecida como Rodovia do Talco que liga a área urbana do município ao seu distrito, denominado Itaiacoca. A área também tem acesso à rodovia BR 376 que liga Ponta Grossa à capital paranaense, Curitiba, a sudeste.

O local é resultado da organização de trabalhadores rurais pelo Movimento dos Trabalhadores Rurais Sem Terra (MST). Segundo diagnósticos realizados pela Incubadora de Empreendimentos Solidários (IESol), a ocupação ocorreu em maio de 2003 e contava com 150 famílias oriundas da região de Ponta Grossa, Palmeira e região metropolitana de Curitiba. Essas famílias estavam acampadas no município de Palmeira desde maio de 2002, numa área emprestada por uma família assentada através do Projeto de Assentamento Palmares II.

Durante a $2^{\circ}$ Encontro da Jornada de Agroecologia, realizada em Ponta Grossa em abril de 2003, parte dos participantes do evento decidiram realizar um protesto contra a realização de pes- 
quisas com sementes transgênicas da Fazenda Experimental da multinacional Monsanto S/A, no bairro Shangrilá do mesmo município, durante esse protesto um grupo de agricultores sem terra ocuparam a área da Fazenda, não obtendo êxito nas negociações.

Foi então que em maio de 2003 decidiram ocupar parte da Fazenda da Empresa Brasileira de Pesquisa Agropecuária (Embrapa), propriedade com aproximadamente 5 mil hectares que deveria ser dedicada à pesquisa e a multiplicação de sementes. Segundo Rocha Filho (2010) o argumento da liderança do MST para a ocupação era que grande parte da área estava sendo arrendada com finalidades econômicas por iniciativa privada para o plantio de pinus elliottii e para o cultivo de culturas de exportação, como soja.

Ainda segundo o diagnóstico da IESol, fruto de negociações com a diretoria da Embrapa, o acampamento foi organizado às margens da Estrada do Talco (PR 513), entre o município de Ponta Grossa e seu distrito Itaiacoca, lugar popularmente denominado pelos acampados de "barranco". Após negociações foi cedida uma área de 660 hectares situada no interior da fazenda, local onde estão atualmente estabelecidos, seus limites estão representados no Mapa de Localização (FIGURA 1). Nesse local as famílias acampadas puderam se organizar como 'Pré-assentamento', ou seja, não se constitui como 'Assentamento' porque a área ainda não está regulamentada mediante o INCRA, e nem pode ser considerado como 'Acampamento', considerando que os trabalhadores rurais já obtiveram avanços nas suas organizações internas, como a demarcação e distribuição de lotes individuais às famílias e a criação da Associação (ATERRA). Lembrando que a área foi cedida pela Embrapa e as famílias vêm aguardando a emissão da posse da terra desde 2003.

A Comunidade Emiliano Zapata conta com 50 famílias, distribuídas em lotes individuais e organizado em 6 núcleos. As famílias são provindas de diversas áreas do Paraná e fora dele, possui predominantemente famílias da região metropolitana de Curitiba, Ponta Grossa e Palmeira. A diversidade de experiências das famílias que hoje compõem o pré-assentamento cria um processo de compartilhamento de múltiplas formas de vivências que necessitam ser negociadas constantemente dentro do grupo e, ao mesmo tempo, com o MST que se organiza em uma escala nacional. O espaço do pré-assentamento, portanto, é um espaço vivo, relacional e exerce uma pressão à mudança, ou como propõe Massey (2008), um espaço de múltiplas possibilidades políticas.

Toda vivência humana implica uma dimensão espacial. O espaço é imprescindível ao corpo vivo em ação no mundo, e a geografia dedicou-se em construir as formas de compreensão do espaço segundo várias tendências teóricas. Dentre elas, a abordagem da Nova Geografia Cultural, aqui representada por Denis Cosgrove e James Duncan, constrói um caminho teórico que possibilita o desenvolvimento da presente pesquisa, superando a noção da morfologia da paisagem, apegada às formas materiais.

As interpretações simbólicas do espaço na geografia, durante algum tempo, estiveram vinculadas aos gêneros de vida e ao estudo das paisagens, dando ênfase às técnicas utilizadas pela sociedade para dominar o meio e concebendo-as como produto desta relação, tal como proposto por Carl Sauer (1996). Tal concepção, fortemente baseada na morfologia da paisagem recebeu muitas críticas por colocar o ser humano como elemento secundário na construção dos significados das paisagens e a negligência das pessoas como seres ativos na construção simbólica (COSGROVE, 1998).

Berque (1998, p. 84) ao discutir o sentido da geografia cultural argumenta: "entendo aqui a geografia cultural como o estudo do sentido (global e unitário) que uma sociedade dá à sua relação com o espaço e com a natureza, relação que a paisagem exprime concretamente". Embora a paisagem seja esta expressão concreta, conforme o autor argumenta, ela não é um espelho refletido, como propõe Meinig (1979). O olhar dos outros sujeitos é o que define seus significados e, portanto, o significado é um ato criativo do sujeito, havendo uma lacuna entre as intenções das ações do criador da paisagem e o receptor da imagem que pode atribuir-lhe significados diferentes da intenção de quem a criou. Para avançar na complexidade da relação entre o sujeito e a paisagem, 
Berque (1998) propõe um modelo de análise que privilegia o sujeito e diferencia a paisagem em seu sentido de marca e matriz:

é preciso compreender a paisagem de dois modos: por um lado ela é vista com um olhar, apreendida por uma consciência, valorizada por uma experiência, julgada (e eventualmente reproduzida) por uma estética e por uma moral, gerada por uma política, etc. e, por outro lado, ela é matriz, ou seja, determina em contrapartida, esse olhar, essa consciência, essa experiência, essa estética e essa moral, essa política, etc (BERQUE, 1998, p. 86).

A visão relacional, proposta pelo autor, que integra sujeito e paisagem num vínculo de "auto-reprodução", no qual a paisagem matriz desenvolve um papel ativo sobre o sujeito, acontece apenas se houver um reconhecimento ou um compartilhamento dos significados atribuídos àquela paisagem, pois, ao contrário, o não reconhecimento impediria a relação de duplo vínculo.

Cosgrove (1998) também coloca o ser humano como ativo no processo de construção de significados da paisagem, mas seus argumentos caracterizam uma paisagem que recebe autonomia em relação ao sujeito, quando afirma que "todas as paisagens possuem significados simbólicos porque são o produto da apropriação e transformação do meio ambiente pelo homem" (COSGROVE, 1998, p.108), ou quando atesta que "as paisagens contêm significados culturais" (COSGROVE, 1998, p. 26). Os significados não são atributos materiais da paisagem, não são elementos que fazem parte dela e, portanto, a paisagem não os "possui" ou "contém"; os significados são criações humanas, é o homem o ser criativo que atribui significados que podem ser reconhecidos e compartilhados ou não por outros homens. O autor apresenta uma perspectiva da paisagem como se os significados estivessem lá à espera de serem "revelados" pelo pesquisador ao argumentar que "revelar os significados na paisagem cultural exige a habilidade imaginativa de entrar no mundo dos outros de maneira autoconsciente e, então, re-presentar essa paisagem num nível no qual seus significados possam ser expostos e refletidos" (COSGROVE, 1998, p. 103).

Embora o raciocínio desenvolvido por esses autores tenha contribuído de maneira especial na construção desta perspectiva de pesquisa, também apontou alguns posicionamentos diferentes que este trabalho deveria seguir para dar conta do objeto proposto. Os argumentos de convergência e grande influência que auxiliaram na construção metodológica deste trabalho tiveram como fonte de inspiração Duncan (1990) em The city as text que considera a paisagem como um sistema de significados a qual, tal qual a linguagem expressa em texto, é depositária e transmite informações. Contudo, as interpretações das informações dependem dos sujeitos que atuarão no processo de recepção e interiorização da informação que por sua vez é determinado e determinante dos valores culturais. Duncan (1990) oferece a compreensão de uma trama de relações em vários sentidos na análise da paisagem e privilegia o ato criativo dos sujeitos sociais através de sua leitura e interpretação, evidenciando as interações entre diversos grupos por um lado, e grande dificuldade de interação interpretativa da paisagem entre grupos que não participavam dos mesmos códigos culturais, por outro. Esse autor cria uma abordagem política da paisagem e afirma que esta deve servir como parte constitutiva da análise de como a vida social é organizada e de como as relações de força que a compõem são constituídas, reproduzidas e contestadas. $\mathrm{O}$ autor utiliza-se do conceito de "intertextualidade" para estabelecer a relação entre os textos históricos e a paisagem, a qual também é um texto, pois é definida como um sistema de significados e práticas que se transformam mutuamente ao longo do tempo.

Assim, tal qual Duncan (1990) buscou conceitos em autores de outros campos científicos fora da geografia para sustentar sua análise como Roland Barthes, Michel De Certeau e Clifford Geertz, este trabalho encontrou apoio conceitual e metodológico na psicologia social baseada na teoria das Representações Sociais da escola de Serge Moscovici. Essa teoria avançou na superação da dicotomia entre o indivíduo e a sociedade a partir da construção do conceito de representação social, definida como "uma modalidade de conhecimento particular que tem como função a elabo- 
ração de comportamentos e a comunicação entre indivíduos" (MOSCOVICI, 1978, p. 26). Na vida cotidiana o sujeito é exigido a pensar e a estabelecer pronunciamentos a respeito de uma série de fatos diários, em que as explicações são elaboradas a partir de uma série de informações e valores colhidos de fontes e experiências múltiplas, sejam elas individuais ou grupais. Para esse autor tais explicações, que são as "representações sociais", são teorias do senso comum, através das quais se procede à interpretação e à construção da realidade social. $\mathrm{O}$ ato de representar é uma reconstrução e não uma repetição ou reprodução, pois neste processo a realidade desconexa, ao ser reconstruída, faz circular e reunir experiências dos indivíduos, tornando o que é estranho em algo familiar para, assim, naturalizá-lo. Neste sentido, a elaboração da Representação Social não é passiva, "mas uma reconstrução do dado em um contexto de valores, reações, regras e associações. Não se tratam de meras opiniões, atitudes, mas de 'teorias' internalizadas que serviriam para organizar a realidade" (LEME, 1993, p. 48).

As RS contribuem na construção da realidade comum, são elaboradas e compartilhadas socialmente, permitindo a comunicação entre os indivíduos mas, embora sejam

formas de conhecimento que se manifestam como elementos cognitivos - imagens, conceitos, categorias, teorias- não se reduzem jamais aos componentes cognitivos [...] são essencialmente, fenômenos sociais que, mesmo acessados a partir de seu conteúdo cognitivo, têm que ser entendidos a partir de seu contexto de produção. Ou seja, a partir de funções simbólicas e ideológicas a que servem e das formas de comunicação onde circulam (SPINK, 1993, p. 300).

Como forma de conhecimento, as RS não podem ser reduzidas nem a um evento intra-individual, em que o social intervém apenas secundariamente, e nem aos fenômenos culturais ou ideológicos. Os indivíduos não são meros processadores de informações e portadores de ideologias, mas são sujeitos ativos que, no processo de interação social, produzem e comunicam suas próprias representações (MOSCOVICI, 1984).

As formas específicas em que as representações sociais estabelecem mediações, materializando a produção simbólica, são a objetivação e a ancoragem. Para Jovchelovitch 1995,

Objetificar é também condensar significados diferentes - significados que frequentemente ameaçam significados indizíveis, inescutáveis - em uma realidade familiar. Ao assim fazer, sujeitos sociais ancoram o desconhecido em uma realidade conhecida e institucionalizada e, paradoxalmente, deslocam aquela geografia de significados já estabelecida, que as sociedades, na maior parte das vezes, lutam para manter (JOVCHELOVITCH, 1995, p. 81-82).

Assim, pode-se dizer que as representações sociais são dinâmicas, emergem como processo, pois são formadas pela sociedade que, simultaneamente, é formada pelas representações. Os processos de ancoragem e objetivação que formam as representações sociais estão atrelados às estruturas históricas e sociais. Tais estruturas, ao mesmo tempo em que são construídas pela ação dos indivíduos, também os sujeita.

Abric (1998), por exemplo, contribui com um importante caminho metodológico, preocupando-se em abordar a estrutura das representações sociais, colocando em segundo plano os processos de ancoragem e objetivação. Tal abordagem é por ele denominada de "teoria do núcleo central", na qual se privilegia o conteúdo cognitivo das representações, que organiza ideias e valores num sistema central e outro periférico. Sua abordagem estrutural constitui-se de elementos cognitivos estruturados, consensuais, rígidos, os quais formam o núcleo central estável que, por sua vez, confere sentido aos elementos mais instáveis, periféricos, que são flexíveis, mutáveis e individualizados. O núcleo central proporciona o sentido global da representação, e o periférico é uma interface com as práticas e situações concretas dos indivíduos.

È necessário explicitar também o caráter mutante das RS, pois quando os sujeitos se encontram para falar de temas de seu interesse e dar sentido ao seu mundo é que as RS são formadas e circu- 
lam constantemente. Cada indivíduo possui uma construção diferenciada dos objetos e cada um acrescenta características e facetas particulares de cada autor e assim "as representações sociais vão sendo transformadas, elas também, em sua construção, sofrem influências provindas dos diversos sujeitos" (GUARESCHI, 2000, p. 37). Sobre o mesmo aspecto, Jovchelovitch (2000) afirma que elas

expressam, em sua estrutura interna, permanência e diversidade, tanto a história como realidades atuais. Elas contêm em si tanto resistência à mudança como sementes de mudança. A resistência à mudança se expressa pelo peso da história e pela tradição, que impinge sobre os processos de ancoragem e objetificação. As sementes da mudança são encontradas no meio essencial das representações sociais, notadamente a conversação (JOVCHELOVITCH, 2000, P. 41).

Por último, mas não em ordem de importância, é preciso ressaltar as relações de poder na criação, circulação e transformação das RS, pois a "construção de relatos jamais é um ato neutro. Alguns relatos produzem uma versão da realidade, outros produzem versos diferentes; o que eles expressam é produto de lutas simbólicas que se relacionam com lutas maiores presentes em todas as sociedades" (JOVCHELOVITCH, 2000, p. 178-179). Sem dúvida, alguns grupos possuem meios mais eficientes que os demais para assegurar sua versão da realidade social e essa diferença é algo a ser considerado e pode ser encontrado na própria estrutura das representações sociais.

Essas relações de poder, contudo, não estão organizadas numa relação unidirecional entre dominantes e dominados, mas diferentemente disso os mesmos elementos do discurso dominante podem estar contidos em vários grupos diferentes, assim como pensa Bourdieu (1989) sobre o poder quando ele é naturalizado, ignorado como arbitrário fazendo parte da visão de mundo dos mais variados grupos sociais, pois

[...] o discurso está perfeitamente ajustado às estruturas sociais. Assim, o poder simbólico não reside nos 'sistemas simbólicos' em forma de uma 'illocutionary force' mas que se define numa relação determinada - e por meio desta - entre os que exercem o poder e os que lhe estão sujeitos, quer dizer, isto é, na própria estrutura do campo em que se produz e se reproduz a crença. O que faz o poder das palavras e das palavras de ordem, poder de manter a ordem ou de a subverter, é a crença na legitimidade das palavras e daquele que as pronuncia, crença cuja produção não é da competência das palavras (BOURDIEU, 1989, 14-15).

Spink (1995) conceitua RS como "estruturas estruturadas" e "estruturas estruturantes" para demonstrar a relação de retroalimentação e das dimensões de análise possíveis, pois "quanto mais englobarmos em nossa análise o tempo longo - e, portanto, os conteúdos do imaginário social - mais nos aproximaremos das permanências que formam os núcleos mais estáveis das representações. No sentido oposto, quanto mais nos ativermos no aqui-e-agora da interação, mais nos defrontaremos com a diversidade e a criação" (SPINK, 1995, p. 122). E é a partir dessa concepção que sugere uma relação entre RS e ideologia pois, para ela, se as RS forem enquadradas no campo estruturado, podem levar à conceituação de ideologia como visão de mundo e, de outra forma, quando se privilegiam as práticas, possibilitam a emergência da ideologia como "representações hegemônicas" a serviço do poder e ainda conclui que, neste sentido, as RS são sempre ideológicas.

A identidade é outro aspecto das representações sociais, que envolve as lutas simbólicas e relações de poder. As RS são construídas a partir de diferentes posicionamentos do sujeito social e isso diz respeito diretamente ao processo de construção identitária. Assim, ao interpretar uma realidade, o indivíduo social também está sujeito a uma identidade, e nesse processo os sujeitos "dizem quem são, como entendem a si mesmos e a outros, como se situam no campo social e quais são os recursos cognitivos e afetivos que lhes são acessíveis em um dado momento histórico" (JOVCHELOVITCH, 2000, p. 177). Dessa forma, as representações sociais só podem ser entendidas a partir da dimensão da alteridade, pois é na diferença entre o "eu" e o "outro" que emergem simultaneamente as representações e as identidades. Spink (1995) argumenta que o sujeito, inserido numa 
situação social e cultural específica, manifesta não apenas respostas individuais, mas manifestações de tendências de seu grupo de pertença ou de afiliação, sendo mais uma vez aqui afirmado o caráter das RS como estruturas estruturadas.

Nesse sentido, as relações de poder, relacionadas aos grupos de pertença, podem permitir a construção de diferentes representações sociais de um mesmo objeto e a apresentação dos contrastes e assimilações. A esse processo Farr (1995) chama de "intertextualidade", argumentando que o indivíduo tanto é um agente de mudança na sociedade como é um produto dessa sociedade. Spink (1995), ao considerar o aspecto da intertextualidade, argumenta que duas forças agem sobre a elaboração das RS, consideradas formas de conhecimento prático que orienta as ações cotidianas:

De um lado temos os conteúdos que circulam em nossa sociedade e, de outro, temos as forças decorrentes do próprio processo de interação social e as pressões para definir uma dada situação de forma a confirmar e manter identidades coletivas. O contexto, neste sentido, é essencialmente 'intertextual'. Ou seja, é a justaposição de dois textos: o texto sócio-histórico que remete às construções sociais que alimentam nossa subjetividade; e o texto - discurso, versões funcionais constituintes de nossas relações sociais (SPINK, 1995, p. 121).

Nesse sentido, deve-se levar em conta uma perspectiva temporal na formação das RS, já que os conteúdos presentes na sociedade possuem origem tanto nos elementos culturais acumulados ao longo do tempo e herdados de gerações passadas, quanto das interações sociais do presente.

$\mathrm{O}$ conceito de representações sociais apresenta muitas convergências com as ideias contidas na produção científica atual da geografia cultural e, neste sentido, podem contribuir mutuamente para produzir novas perspectivas de pesquisa em ambos os campos científicos. Ao comparar, por exemplo, as proposições de Berque (1998) pode-se evidenciar uma mesma perspectiva teórica. O argumento do geógrafo sobre seu entendimento da geografia cultural, não é demais repeti-lo, é que esta deve ser entendida como "o estudo do sentido (global e unitário) que uma sociedade dá à sua relação com o espaço e com a natureza, relação que a paisagem exprime concretamente" (BERQUE, 1998, p. 84).

As proposições de Berque (1998) que analisa a paisagem enquanto marca e matriz e estabelece entre elas inúmeros laços de co-determinação, desenvolvendo um caráter processual de reprodução, podem ser identificadas com a argumentação de Spink (1995) sobre sua visão da representação social como estrutura estruturada e estruturante, que também apresenta a mesma relação processual e uma co-determinação entre ambas. Conclui-se que em ambas as abordagens está presente a visão construtivista da realidade social, atribuindo ao sujeito um papel criativo.

Duncan (1990) utiliza o conceito de "intertextualidade" para estabelecer a relação entre a influência dos textos históricos e as paisagens e rituais produzidas por gerações posteriores, ocorrendo nesse processo uma transformação dos significados atribuídos a ambos. O autor reforça aqui o papel das tradições na formação dos significados, mas acrescenta que a ação do sujeito do presente pode atribuir valores diferentes ao passado. Ou seja, quando o sujeito se "apropria" dos textos do passado, para usar o termo de Chartier (1992), ele o transforma segundo novos significados atribuídos a partir de elementos do presente.

A abordagem de Spink (1995) contempla a "intertextualidade" quando argumenta que o contexto não é marcado apenas por fatores da situação atual, mas também pelos diferentes tempos históricos que permeiam a construção de significados, pois os conteúdos das representações sociais podem ter origens nos mais diferentes tempos históricos, tanto os remotos como atuais, transformando ambos.

Como pode ser visto, há uma vasta possibilidade de diálogo entre a geografia e a psicologia social, a partir do conceito de representações sociais. Contudo, o estudo das representações sociais tem negligenciado a dimensão espacial da sociedade que com certeza enriqueceria a pesquisa neste campo de conhecimento. Pode-se argumentar que a própria formação da representação social que envolve os processos de ancoragem e objetivação, as quais estão atreladas às estruturas históricas 
e sociais, estão também atreladas ao espaço. Como conhecimento construído por leigos em seu cotidiano, estão intrincados no espaço, pois os homens trabalham, moram, caminham, compram, enfim realizam uma série de ações na vida diária. Assim, é a partir do espaço, concebido como uma criação humana que condiciona seus criadores, que se pode desenvolver as percepções, a comunicação entre os indivíduos. Todos esses processos são elementos constitutivos das representações sociais que, por sua vez, vão ser também constitutivas do espaço.

Enfim, uma representação social é sempre de alguém - o sujeito, e de alguma coisa - o objeto, havendo a necessidade, ao construir um objeto de pesquisa, que se leve em consideração sujeito e objeto da representação que se quer estudar de forma simultânea, conforme alerta Sá (1998). Assim, pode-se dizer que a representação está na relação entre ambos sujeito/objeto, e esta pesquisa é uma contribuição para a análise relacional entre indivíduo, sociedade e espaço, construída na intersecção entre o objetivo, o subjetivo e o intersubjetivo, utilizando o conceito de representação social, o qual pode servir de ferramenta explicativa da construção da trama simbólica que envolve a estruturação do espaço do Pré-assentamento Emiliano Zapata.

\section{TRABALHO E RELAÇÕES POLÍTICAS COTIDIANAS: elementos de unidade e tensão na estruturação das Representações Sociais do pré-assentamento Emiliano Zapata.}

As famílias do Pré-assentamento Emiliano Zapata, mesmo depois de tantos anos estabelecidos no mesmo local, ainda não possuem as condições necessárias para serem beneficiadas por políticas públicas ou créditos rurais. Isso porque, apesar do tempo, ainda não receberam a Titulação de Assentamento, documento emitido pelo INCRA, que os asseguram o domínio do uso e acesso a terra. Essa condição traz insegurança e desamparo para os moradores, como mostra o trecho de entrevista abaixo:

Então a gente corre atrás pra ser regularizado pra não depender que você venha fazer os teus trabalhos e de repente vem um fazendeiro e diz que você tem que sair (J.C.) .

A produção rural demanda investimentos e o pequeno retorno advindo da venda de sua colheita ocorre de forma muito lenta, trazendo ainda mais preocupações para essas pessoas. Os investimentos na produção são incertos, somado a isso, os investimentos na propriedade e na residência também geram inquietações, na medida em que podem ter o mínimo de previsão sobre o futuro do estabelecimento. A constante queixa dos moradores não é só pela prolongada espera da regularização da área pelo Instituto Nacional de Colonização e Reforma Agrária (INCRA), mas também, pelo receio de não continuarem no lote demarcado, obedecendo a distribuição realizada segundo critérios dos próprios moradores, como evidencia o trecho de entrevista:

Então a gente tá e não ta, que nem eu falo, enquanto o INCRA não vem, não tem nada decidido. É, fica difícil, a gente quer construir, mas ao mesmo tempo tem medo (M.A.) .

A renda das famílias moradoras é proveniente da venda individual de sua produção e ainda da parceria com a Companhia Nacional de Abastecimento (CONAB), o que garante um mínimo de rendimento fixo mensal, mesmo que seja abaixo de um salário mínimo, segundo Rocha Filho (2010). Nesse sentido as famílias têm elaborado fontes alternativas de renda, segundo o Diagnóstico da IESol, há um grande número de pessoas trabalhando esporadicamente fora da Comunidade, em sua maioria como pedreiro ou servente de pedreiro, ou cortando madeira nas propriedades rurais vizinhas.

Para serem contemplados por essa parceria os trabalhadores e trabalhadoras rurais necessitariam estar organizados em uma associação ou cooperativa, o que foi viabilizado pela existência da Associação dos Trabalhadores Rurais da Reforma Agrária (ATERRA). A organização de pessoas 
trabalhadoras, integrantes do MST em torno de associações e cooperativas possibilita, além da inserção econômica pela produção agrária, mas auxilia na própria estrutura do movimento, intensificando a pressão pela regularização das áreas ocupadas.

O trabalho cotidiano das pessoas do pré-assentamento também gira em torno da Horta Comunitária e da Unidade de Processamento de Alimentos Agroecológicos organizada com o auxílio da Incubadora de Empreendimentos Solidários (IESol) da Universidade Estadual da Ponta Grossa (UEPG).

O Pré-assentamento apresenta elementos comuns como a luta pela terra e a precária situação sócio-econômica de seus integrantes. Essa similaridade pode nos remeter a caracterizar o grupo como um coletivo homogêneo internamente. Entretanto, apesar da homogeneidade geral, quando se observa o grupo na escala do assentamento, passam a ser visíveis uma série de elementos de heterogeneidade que estão, conforme Massey (2008), em permanente movimento de construção. Afinal,

as inserções e situações sociais não são jamais completamente idênticas, os múltiplos processos que intervêm nas tomadas de posição são também variados. Essa dupla fonte de variação pode gerar uma multiplicidade aparente de tomadas de posição que são, entretanto, produzidas a partir de princípios organizadores comuns (DOISE, 1990, p.127 apud SÁ, 1996, p. 34).

Assim, o pré-assentamento apresenta uma pluralidade de representações que podem conter significados comuns ou divergentes em um processo de co-exitência e negociação constante entre pessoas que viveram distintas trajetórias de vida e que passam a constituir juntos, o espaço do pré-assentamento Emiliano Zapata, juntamente com o MST.

Os entrevistados apresentaram em sua maioria, origem rural, embora grande parte deles expressaram ter migrado para cidade e dela aderiram ao movimento. A causa motivadora para a entrada ao Movimento está igualmente dividida, entre as evocações, entre exclusão rural (20\%), e exclusão urbana (20\%), mas a motivação maior ainda é afetiva relacionada a vínculos familiares $(50 \%)$ e demais se referem a convites de amigos (10\%). As pessoas convidadas por familiares para integrar o movimento alegam uma possibilidade de "re-união familiar". Assim, observa-se que, mais do que a ideia objetiva de integração ao MST, por meio de posição política e ideológica, há um componente afetivo relacionada aos vínculos familiares.

Sobre o período de acampamento, constatou-se que apenas $50 \%$ dos entrevistados haviam participado do acampamento. É importante ressaltar que a história do acampamento é fundamental para a criação de laços identitários. Esse período é marcado pela organização coletiva do trabalho, por estratégias organizativas e territoriais, vivência coletiva de situação de precariedade elaborando assim nos acampantes, um sentimento de pertencimento comunitário. Essa realidade é evocada pelas pessoas que vivenciaram a fase de acampamento e se mostra como um elemento significante de sua espacialidade atual:

A comunidade dispersou, tem muita gente só pra si, entendeu? Foi pra lá, está lá esquece de amizade, quando era o acampamento aqui todo mundo se conversava, todo mundo se encontrava, agora não, o povo está lá, cada um se isolou, mas assim, eu não vou na casa dos vizinhos, porque é muito longe e depois eu ando muito cansada ultimamente (L.E.N.)

Quando questionados sobre ocorrências de conflitos com a população do entorno do pré-assentamento, da ocupação até os dias atuais, os relatores evidenciaram que houve problemas. $38,5 \%$ afirma que há aceitação de sua presença pelo entorno. Já 46,1\% afirma haver despejos (dessas afirmações 62,5\% relatam despejos posteriores ao estabelecimento na área cedida pela Embrapa, referindo a proprietários vizinhos, o restante, se referem ao despejo ocorrido na primeira ocupação da área em 2003). O restante do total das evocações (15,4\%), afirmaram haver algum tipo de conflito, trazendo nomes específicos do proprietário vizinho.

Sobre a organização interna e as lideranças do pré-assentamento apresentam uma complemen- 
taridade, trazendo a participação em assembleia como ação fundamental, associado como papel das lideranças nas tomadas de decisão. Assim, embora as assembleias sejam um espaço fundamental para corroborar o caráter coletivo das decisões, há uma forte influência de algumas pessoas que se tornam referência para as ações. As evocações sobre a organização do pré-assentamento trazem $43,7 \%$ relacionadas à importância das assembleias e 37,5\% sobre a importância das lideranças. $12,5 \%$ apresenta um descontentamento com a liderança. O restante das evocações $(6.3 \%)$ foram dispersas, sem possibilidade de reunião em um eixo explicativo.

Quando solicitados a refletir sobre as expectativas em relação a possibilidade de regularização da terra, o discurso dos entrevistados mescla tanto os benefícios individuais como coletivos. 66,7\% apontou que a regularização traz um favorecimento ao lote, de forma individual, e 33,3\% trouxeram a ideia coletiva do fortalecimento do pré-assentamento. Os argumentos em torno dos benefícios aos lotes estavam relacionados à segurança da produção familiar, considerando seus investimentos, bem como possibilidade de melhoria da infra-estrutura da moradia. Já as evocações ligadas ao pré-assentamento de forma mais coletiva fizeram referências ao fortalecimento da comunidade, possibilidade de expansão da produção e a instituição de um novo modelo de agricultura sustentável.

Os relatos dos entrevistados em torno do MST e de seus participantes apresenta três tendências.

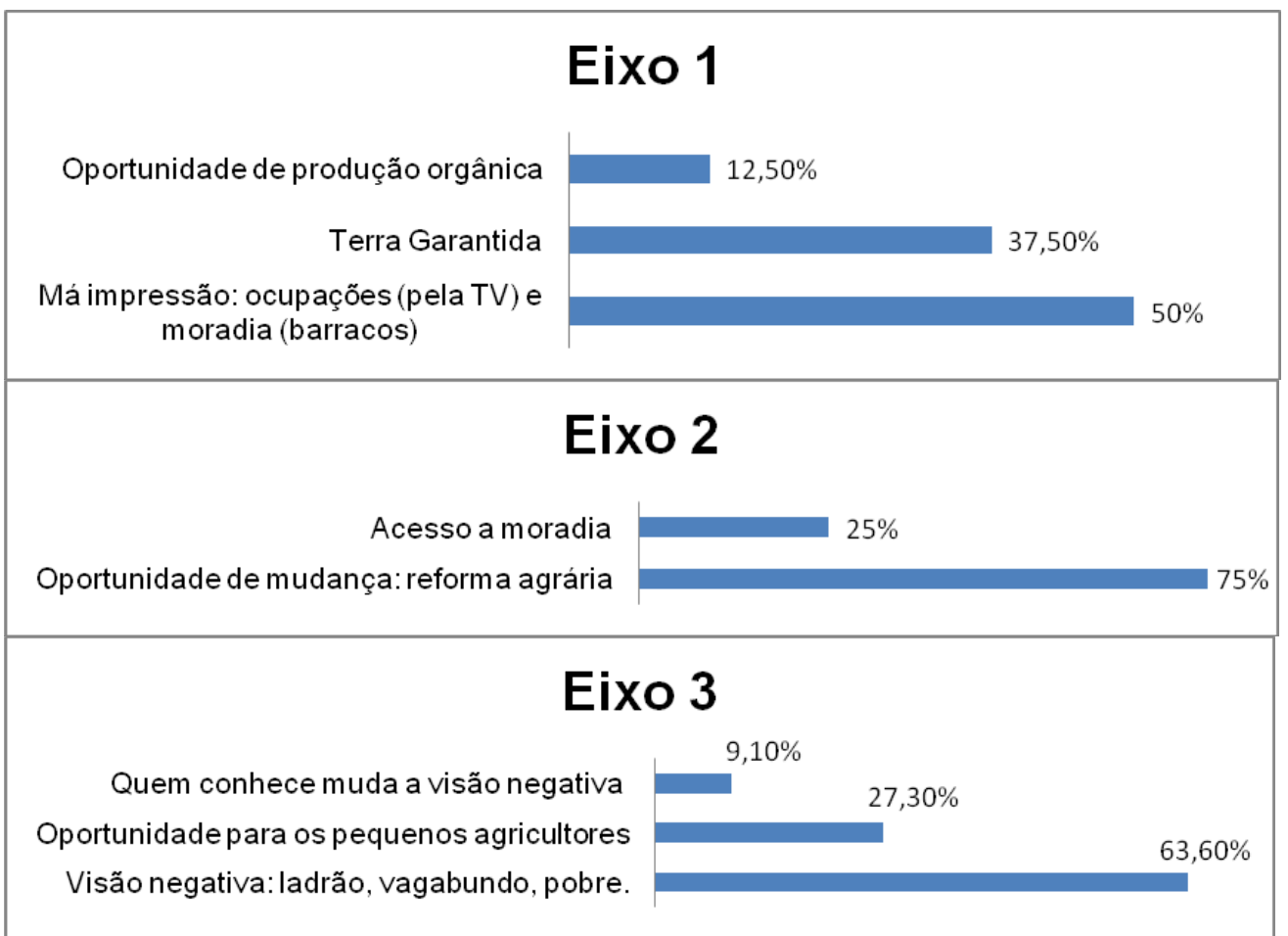

Figura 1 - Gráfico dos Relatos sobre o MST.

O primeiro eixo organizado do Gráfico acima é referente ao período anterior à sua participação no movimento, ficando expressiva a má impressão em torno da pobreza e dos barracos de lonas pretas (50\%), características dos acampamentos dos sem-terra. O segundo eixo, retrata a vivência do entrevistado no movimento, onde ficou evidente a ideia de que o movimento é um agente de transformação social e de luta pela distribuição da riqueza $(75 \%)$. O terceiro eixo se relaciona àquilo que os entrevistados pensam a sociedade imaginar sobre eles, aparecendo com maior frequência a imagem social negativa $(63,6 \%)$, associada à agressividade, ao roubo e à bagunça. Contudo, acreditam ser essa imagem social modificada, quando as pessoas conhecem a área de perto e reconhecem sua organização $(9,1 \%)$.

O sentimento de adaptação ao local e de como a área do Pré-assentamento Emiliano é sig- 
nificada pelos entrevistados também foi tema presente no discurso que traz algumas importantes tendências. A primeira está relacionada com a satisfação dos moradores em viver no local e habitar numa área rural que liga com sua identidade de morador do campo.

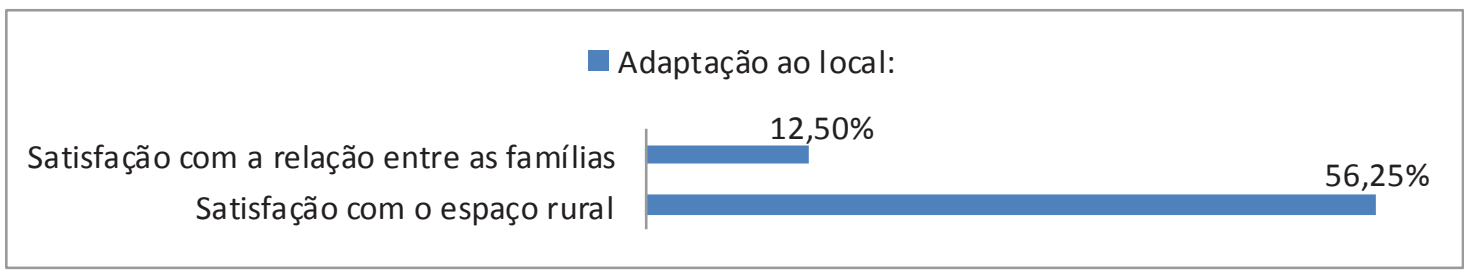

Figura 2 - Gráfico da Adaptação ao local.

Os 31,25\% restantes (Figura 2) formam outro importante eixo que se referencia ao pré-assentamento como um espaço de pressão à mudança social e de luta pelo direito à terra e à moradia. Dessas evocações, $66,7 \%$ apresenta como finalidade de seus esforços a mudança do próprio local, a Comunidade Emiliano Zapata, enquanto que 33,3\% expressa como intenção uma contribuição ao MST como um movimento nacional.

Outro elemento que tensiona o cotidiano do Pré- Assentamento são as relações que envolvem a liderança. Esta expressa a organização das ações da comunidade que afetam o cotidiano das famílias assentadas, além de constituir o elo entre a estrutura organizativa do MST e a área em questão.

O termo 'liderança', é proposital por ser um termo que discursivamente é conflitante com as ações do MST. Mesmo que os assentamentos organizados pelo MST sejam compostos por dirigentes que cumprem a função de facilitar o diálogo entre as famílias e os propósitos do MST, o movimento também se posiciona contra qualquer poder centralizado, primando sempre por atividades coletivas, sob decisões democráticas participativas.

É preciso compreender que o MST como um movimento social possui objetivos de transformação social, para isso necessita que seus seguidores incorporem propostas diferenciadas de organização político social. Em escala nacional, o MST se organiza em lideranças que atendam promover esse pensamento de mudança e instituição de alternativas a uma lógica hegemônica. Esse pensamento traz consigo um discurso a favor de ações coletivas e contra lideranças pontuais. Portanto a coordenação deve refletir uma liderança motivadora e circunstancial, tendo a função de promover os ideais do MST e interferir quando eles, porventura, são tensionados.

Os relatos dos entrevistados sobre a organização interna apresentam as assembleias, como principal forma de organização para decisões coletivas, como mostra a Figura 3:

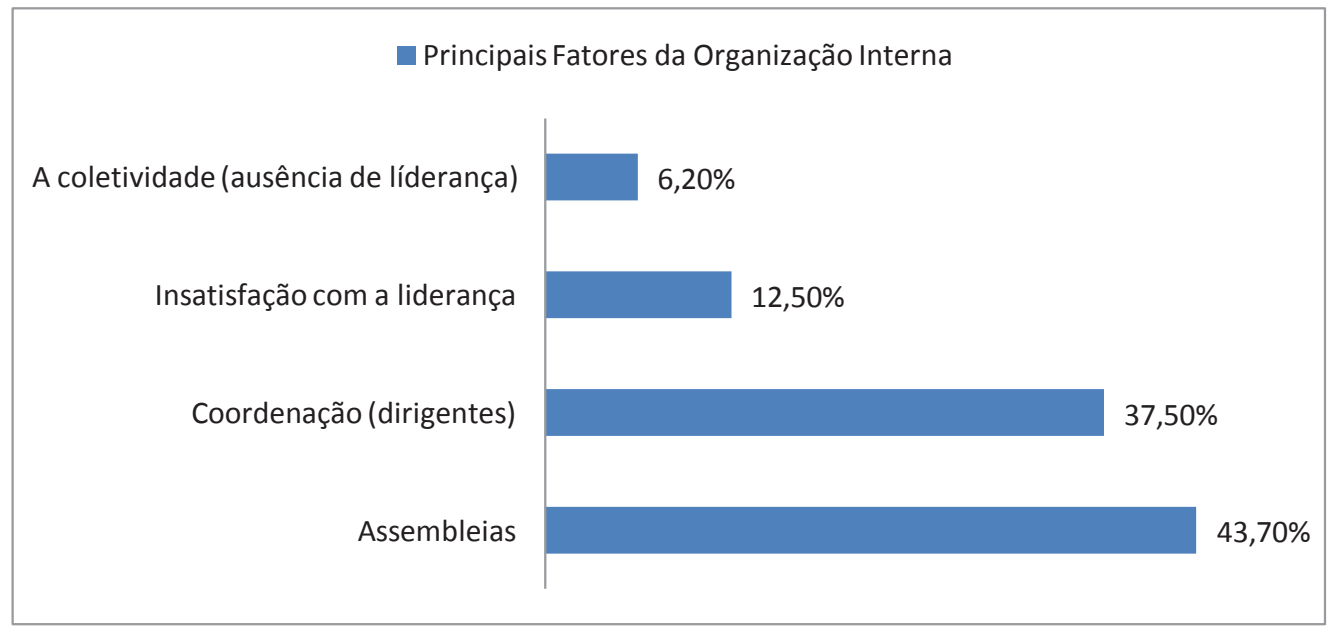

Figura 3 - Gráfico dos Principais fatores da organização interna. 
As assembleias apresentam-se como um eixo majoritário das representações (43,7\%), o que quer dizer que os moradores legitimam as decisões tomadas por meio de assembleias e se sentem representados por ela. Também é expresso como centralidade nas representações, a importância dada a coordenação (37,5\%), tomando algumas pessoas como referências nas ações e decisões em torno da comunidade. Nesse sentido há um reconhecimento simultâneo das práticas organizacionais como a assembleia que busca a participação coletiva nas decisões, como também está presente o reconhecimento de lideranças individuais, que seriam pessoas engajadas no Movimento e tornam-se cotidianamente referencia para o grupo.

A distribuição e delimitação dos lotes individuais familiares é um exemplo de decisão que demandou a participação de todos. Sobre esse episódio, é possível perceber na Figura 4 que os entrevistados afirmam na maioria (60\%) ser a distribuição dos lotes decidida em assembleia, dado a dar uma legitimidade ao próprio caráter coletivo do pré-assentamento. Contudo, 26,6\% das evocações afirmam que houve alguns critérios a privilegiarem algumas famílias, com base, por exemplo, no tempo de participação das atividades do MST.

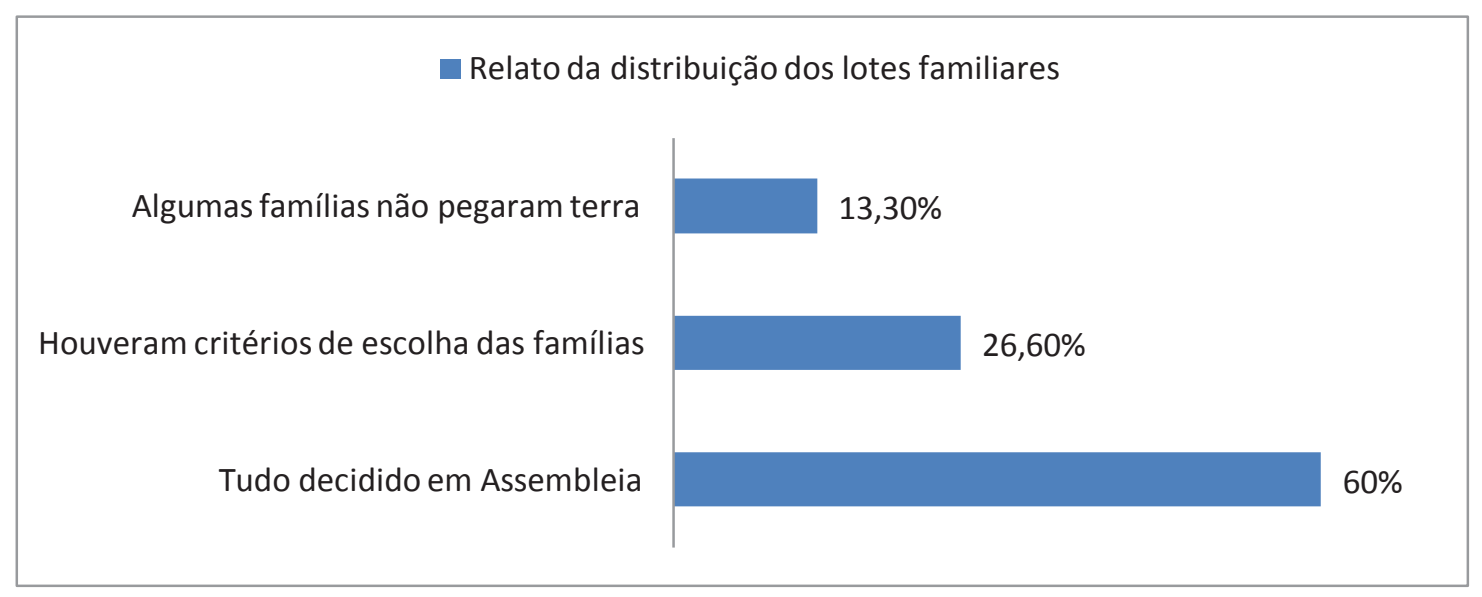

Figura 4 - Gráfico Sobre Relato da distribuição dos lotes familiares.

Retomando a figura 3, de forma periférica (12,5\%) aparece a insatisfação dos entrevistados com as decisões que determinado grupo vem tomando para o destino do Pré-assentamento. Fato que, mesmo de maneira mais dispersa nas representações, expressa a complexidade da implementação dos objetivos do MST na escala local cotidiana.

O MST prega a mudança nas bases produtivas e formas coletivas de tomada de decisão, esse pensamento subverte com as ações que se realizam na vida cotidiana de uma sociedade capitalista. Rocha Filho e Cunha (2009) comentam as dificuldades de ação coletiva em áreas em que os moradores assentados ainda desenvolvem práticas individualistas, inibindo uma mudança social efetiva.

As práticas cotidianas desenvolvidas pelas propostas do MST para superar a postura individualista são formas cooperativas e coletivas de estruturação social, conforme aponta Comparato (2001). Contudo, o movimento esbarra na dificuldade de atender a pluralidade de trajetórias de vidas, práticas culturais, contextos sócio-econômicos, enfim, a multiplicidade presente num espaço de assentamento.

Apesar dos apontamentos anteriores o MST, como uma organização multi-escalar, tem conseguido desenvolver suas frentes de ação, colocando-se como uma organização essencial na luta pela terra e na promoção de alternativas econômicas e políticas. O pré-assentamento Emiliano Zapata não é apenas um reflexo dos objetivos do MST, mas uma síntese de relações que se fazem em negociações locais (entre os moradores do pré-assentamento), regionais (entre o assentamento e os espaços de vizinhança) e nacional (envolvendo as políticas federais e o MST). Nesse sentido, 
o pré-assentamento é um espaço complexo e se constitui como possibilidade, sempre aberto às negociações necessárias na vida cotidiana.

\section{CONSIDERAÇÕES FINAIS}

Esse artigo investigou a relação entre as Representações Sociais do Pré-assentamento Emiliano Zapata construídas pelos seus moradores e o espaço por elas constituído. Foi evidenciado que o espaço se faz para além de suas formas materiais e os conteúdos das representações sociais são suas partes constitutivas.

As representações sociais são construídas por elementos de múltiplas escalas, envolvendo um processo de negociação constante entre interesses multiescalares. As ações do MST são fruto de um debate macro, mesclado com as realidades locais que se fazem no cotidiano das famílias, indivíduos que formam e organizam o pré-assentamento.

A pesquisa encontrou no local, um espaço de diálogo entre uma ideologia coesiva representada pelo MST, que organiza o pré-assentamento, e a diversidade cultural de famílias ali residentes. É essa pluralidade de elementos convergentes no pré-assentamento Emiliano Zapata que o torna um espaço singularizado, vivo, que pressiona à mudanças sociais.

\section{REFERÊNCIA BIBLIOGRÁFICA}

ABRIC, Jean-Claude. A abordagem estrutural das representações sociais. In: MOREIRA Antonia Silva Paredes e OLIVEIRA, Denise Cristina de (orgs.). Estudos Interdisciplinares de representação social. Goiânia: AB, 1998.

BARDIN, Lawrence. Análise de conteúdo. Lisboa: Edições 70, 1977.

BERQUE, Augustin. Paisagem-Marca, Paisagem-Matriz: elementos da Problemática para uma Geografia Cultural. In: CORREA, Roberto Lobato e ROSENDAHL, Zeny (orgs.) Paisagem, tempo e cultura. Rio de Janeiro: Ed UERJ, 1998.

BOURDIEU, Pierre. O poder simbólico. Rio de Janeiro: Bertrand, 1989.

CHARTIER, Roger. Textos, impressões, leituras. In: HUNT, Lyn. A nova história cultural. São Paulo: Martins Fontes, 1992.

COMPARATO, B. K. A ação política do MST. São Paulo em Perspectiva, v. 15, número 4. São Paulo, Out/Dez. 2001.

COSGROVE, Denis. Em direção a uma geografia cultural radical: problemas da teoria. Espaço e cultura. n. 5- (jan-jun/98. Rio de Janeiro: UERJ, NEPEC, 1998.

DUNCAN, James Stuart. The city as text: the politics of landscape interpretation in the Kandyan Kingdom. Cambridge: Cambridge University Press, 1990.

FARR, Robert M. Representações sociais: a teoria e sua história. In: GUARESCHI, Pedrinho e JOVCHELOVITCH, Sandra. Textos em representações sociais. Petrópolis: Vozes, 1995.

GUARESCHI, Pedrinho. Representações e ideologia. Revista de Ciências Humanas - Representações sociais e interdisciplinaridade. / Universidade Federal de Santa Catarina. Centro de Filosofia e Ciências Humanas. v. 1, n. 1 (jan. 1982). Florianópolis: Editora UFSC, 2000.

JOVCHELOVITCH, Sandra. Vivendo a vida com os outros: intersubjetividade, espaço público e representações sociais. In: GUARESCHI, Pedrinho e JOVCHELOVITCH, Sandra. Textos em representações sociais. Petrópolis: Vozes, 1995.

JOVCHELOVITCH, Sandra. Representações sociais e esfera pública: A construção simbólica dos espaços públicos no Brasil. Petrópolis: Vozes, 2000.

LEME, M. A. V. O impacto da teoria das representações sociais. In: SPINK, Mary Jane (org.). O conhecimento no cotidiano. As representações sociais na perspectiva da psicologia social. São Paulo: Brasiliense, 1993. MASSEY, Doreen. B. Pelo Espaço: uma nova política da espacialidade. Rio de Janeiro: Bertrand Brasil, 2008. 
MOSCOVICI, Serge. A representação social da psicanálise. Rio de Janeiro: Zahar, 1978.

MOSCOVICI, Serge. The phenomenon of social representations. In: FARR, R. M. e S. MOSCOVICI. Social representations. Cambridge: Cambridge University Press, 1984.

ROCHA FILHO, A. N; CUNHA, L. A. G. Economia solidária: alternativa de desenvolvimento, geração de trabalho, renda e resistência à exclusão social. Emancipação, Ponta Grossa, 9(1): 95-105, 2009.

ROCHA FILHO, A.N. A ATERRA - Associação dos Trabalhadores Rurais da Reforma Agrária: Desafios, obstáculos e contradições na construção e organização de uma alternativa de Economia Solidária. Ponta Grossa, UEPG, PMCSA, 2010.

SÁ, Celso Pereira de. Sobre o núcleo central das representações sociais. Petrópolis: Vozes, 1996.

SÁ, Celso Pereira de. A construção do objeto de pesquisa em representações sociais. Rio de Janeiro: EdUERJ, 1998.

SAUER, Carl O. Geografia cultural. Espaço e cultura. no 3, dez-1966, Rio de Janeiro: UERJ, NEPEC, 1996. SPINK, Mary Jane. O estudo empírico das representações sociais. In: SPINK, Mary Jane (Org.). O conhecimento no cotidiano. As representações sociais na perspectiva da psicologia social. São Paulo: Brasiliense, 1993.

SPINK, Mary Jane. Desvendando as teorias implícitas: uma metodologia de análise das representações sociais. In: GUARESCHI, Pedrinho e JOVCHELOVITCH, Sandra. Textos em representações sociais. Petrópolis: Vozes, 1995.

Trabalho enviado em setembro de 2012

Trabalho aceito em outubro de 2012 